\title{
MULTIKULTURALISME USADA BALI
}

\author{
Ida Bagus Suatama \\ Program Studi Kesehatan Ayurweda, Fakultas Kesehatan \\ Universitas Hindu Indonesia Denpasar \\ E-mail : idabagussuatama60@gmail.com
}

\begin{abstract}
Abstrak
Dua sistem pengobatan yang berkembang di era milenial saat ini adalah sistem Bio Medis kedokteran dan sistem Bio Kultural atau pengobatan tradisional. Usada Bali merupakan sistem pengobatan tradisional Bali yang sampai sekarang masih dilakukan di Bali. Usada Bali merupakan turunan dari Ayurweda. Ayurweda merupakan bagian dari Upaweda, sedangkan Upaweda merupakan bagian dari Weda Smerti. Masuk ke Bali pada abad X pada jaman Pemerintahan Raja Udayana. Sistem Usada Bali dasarnya adalah Empiriko Logis Magis Religius (pengalaman yang masuk akal dan ada unsur magis dan religious). Sistem pengobatan tradisional oleh WHO diakui sebagai Tradisional Medicine / Complementary and Alternative Medicine (TM/CAM). Kedatangan Dokter Wolfgank Von Wack tahun 1937 bertugas di Bali merupakan sebuah petunjuk bahwa Usada Bali kena pengaruh modernism. Secara legal formal sistem pengobatan Usada Bali mulai selangkah demi selangkah terpinggirkan. Dengan adanya regulasi Dasar Hukum legal formal dari Pemerintah tentang Pengobatan Tradisional, Usada Bali mulai mendapat perhatian. Gubernur Bali saat ini telah mempublikasikan dan akan menyediakan media bagi para Balian untuk praktek. Ketua IDI (Ikatan Dokter Indonesia) menyatakan Balian dapat bersinergi bila telah melewati standarisasi Fitofarmaka yang berlaku. Kepala Dinas Kesehatan Provinsi Bali dan Rektor Universitas Hindu Indonesia menyambut dengan baik regulasi ini. Sekarang kesempatan dunia akademik mendapat peran lebih banyak agar Sistem Pengobatan Usada Bali semakin maju. Dalam penelitian ini diajukan tiga masalah yaitu: (1) Bagaimanakah eksistensi Usada Bali? (2) Bagaimanakah Usada Bali dalam multikulturalisme? (3) Dapatkah Usada Bali menunjang kehidupan masyarakat Bali?
\end{abstract}

Kata Kunci: Multikulturalism, Usada Bali

\begin{abstract}
The two medical systems that developed in the millennial era are Bio medical systems of medicine and Bio Cultural systems or traditional medicine. Usada Bali is a system of traditional Balinese medicine which is still carried out in Bali. Usada Bali is derived from Ayurvedic medicine. Ayurvedic is part of Upaweda, while Upaweda is a part of Vedic Smerti. Entered Bali in the X century in the era of King Udayana's reign. The Usada Bali system is basically the Logical Empiricist Magical Religion (a reasonable experience and there are magical and religious elements). The traditional medical system by WHO is recognized as Traditional Medicine / Complementary and Alternative Medicine (TM / CAM). The arrival of Doctor Wolfgank Von Wack in 1937 serving in Bali was a clue that Usada Bali was affected by modernism. Formally, the Usada Bali medical system starts step by step marginalized. With the existence of basic regulations on formal legal law from the Government regarding Traditional Medicine, Bali Usada began to get attention. The current Governor of Bali has published and will provide media for the Balians to practice. The Chairperson of IDI (Indonesian Doctors Association) stated that Balian could work together if it had passed the applicable Fitofarmaka standardization. Head of Bali Provincial Health Office and Chancellor of the Indonesian Hindu University welcomed the regulation. Now the opportunity for the academic world to get a greater role so that the Usada Medical System in Bali will progress. In this study three problems were proposed, namely: (1) How is the existence of Usada Bali? (2) How is Usada Bali in multiculturalism? (3) Can Usada Bali support the lives of Balinese people?
\end{abstract}

Keywords: Multiculturalism, Usada Bali 


\section{Pendahuluan}

Dalam Antropologi Medis, secara teoritis sistem pengobatan dibagi menjadi 2 yaitu, sistem medis modern dan sistem medis tradisional, seperti yang dijelaskan oleh Sikkink (2009;3) "Within medical anthropology a distinction is often made between biomedicine, or western medical sistem and ethno medicine, or the local system of indigenous beliefs and practices surrounding health and illness". Penjelasan tersebut menunjukkan bahwa sistem medis modern adalah sistem biomedis (biomedicine) yang berkembang di dunia barat. Sedangkan sistem medis tradisional adalah etnomedis (ethno medicine) yang berkembang pada sistem pengobatan lokal dan berbagai kepercayaan kesehatan yang berkembang di berbagai etnis. Kedua sistem ini masingmasing berdiri sendiri menurut sistem pengobatan atau konsep dan teori yang mendasari (Foster and Anderson 2013;1)

Pengertian multikulturalisme memiliki dua ciri utama, yaitu (1) kebutuhan terhadap pengakuan (the need of recognition) dan (2) legitimasi keragaman budaya atau pluralisme budaya. Multikulturalisme adalah sebuah idiologi yang mengakui perbedaan dalam kesederajatan. Multikulturalisme merupakan uraian dari teori perbedaan yang diilhami gagasan posmodernisme. Paradigma multikulturalisme merupakan perbedaan sebagai suatu kerja yang ada didalamnya untuk menghargai banyak kelompok dan narasi khas mereka masing-masing. (Triguna, 2008, 124)

\section{Sejarah Singkat Usada Bali}

Prof. dr. I Gusti Ngurah Nala dalam majalah USADHA (hal. 4 - Edisi 1 - 2007) menjelaskan secara panjang lebar sejarah usada di Bali. Ketika masalah pengobatan telah berkembang pesat di India terjadi hubungan langsung antara India dan Indonesia pada abad $\mathrm{V}$.

Hubungan yang erat antara Bali dan Jawa mulai terjadi pada abad ke X, ketika Raja Dharma Udayana menikah dengan Putri Mahendradatta dari Jawa Timur. Disusul dengan kedatangan seorang $\mathrm{Mpu}$ dari Jawa Timur yang diberi gelar Mpu Kuturan. Beliau menata pulau Bali dalam segala hal, baik pemerintah, tempat suci, awig-awig dan masalah kesehatan. Masalah kesehatan ini secara jelas disebut dalam Lontar Taru Pramana. Pada pemerintahan Raja Waturenggong di Gelgel Bali (tahun 14601550), datanglah seorang Bhagawan dari Jawa Timur yang bernama Dang Hyang Dwijendra. Pada jaman ini penulisan naskah usada mendapat prioritas utama, dalam penataan keterampilan dan kemampuan secara professional, masing-masing ada Ista Dewatanya atau aktornya, contoh :

- Bhagawan Wrhaspati sebagai Mpu nya ajaran agama

- Bhagawan Wiswakarma sebagai Mpu nya ajaran menata bangunan, daerah dan tata kota

- Bhagawan Mredu sebagai Mpu nya Jyotisa atau Wariga

- Bhagawan Kasyapa sebagai Mpu nya Usada atau para Balian. (Pusdok, 26; 1996)

\section{Jenis-Jenis Balian}

Dalam buku Heilkunde und Volkstum auf Bali oleh dr. Wolgang von Weck (1937) dan dalam buku Usada Bali oleh I Gusti Ngurah Nala (1993) telah dipaparkan tentang jenis-jenis balian yang ada dalam masyarakat Bali yang mana sebagai praktisi Usada Bali, anatara lain:

- Balian Ketakson, yaitu Balian yang dalam praktek pengobatannya memanggil Ista Dewata nya untuk memasuki tubuhnya sehingga balian tersebut Ketakson / Kerasukan / Trance. Makanya balian tersebut dinamakan Balian Ketakson.

- Balian Kapican, yaitu Balian yang dalam praktek pengobatannya menggunakan sarana berupa keris, permata, bagian-bagian dari tumbuhan atau binatang. Sarana ini didapat saat melakukan persembahyangan atau meditasi dengan kusuk, sarana ini disebut Pica / pemberian dari alam gaib.

- Balian Usada, yaitu Balian yang dalam praktek pengobatannya menggunakan acuan dari kepustakaan 
Usada, keterampilan ini didapatkan dari mempelajari Lontar-Lontar Usada ditambah dengan adanya faktor keturunan, sehingga Balian Usada menjadi mantap.

- Balian Campuhan, yaitu Balian yang dalam praktek pengobatannya menggunakan teknik campuran dari keterampilan tersebut diatas, tidak tertutup kemungkinan seorang praktisi kesehatan modern merangkap sebagai Balian Usada Bali.

Angelo Hobart menyatakan "As long as the Hindu religion remain steadfast, people will continue to believe the seen and umseen worlds, and there will be traditional healers". (Selama orang-orang yakin dengan agama Hindu, akan tetap ada kepercayaan sekala dan niskala, selama itu balian akan tetap ada. (Mbete, 1988)

Prastika (2017) dalam disertasinya berjudul "Yoga Sastra Laku Mistik Balian Usada Bali" menemukan bahwa pengakuan dan penghargaan masyarakat Bali terhadap Balian masih tinggi, sehingga menjadi tantangan bagi para Balian untuk mengembangkan pengetahuan dalam bidang pengobatan, termasuk melalui Yoga Sastra. Yoga Sastra adalah salah satu bentuk yoga dengan jalan mempelajari sastra-sastra usada dan Ayurweda.

\section{Sumber Bahan Tamba atau Obat Usada Bali}

Ada beberapa jenis bahan obat dalam praktek pengobatan tradisional Usada Bali, antara lain:

\section{a. Taru Pramana / Pohon Berkhasiat Obat}

Taru Pramana sungguh populer dalam masyarakat Bali sebagai bahan obat keluarga. Taru Pramana ini mulai dari bunga, daun, buah, batang, kulit, akar, dan umbi dapat dipergunakan sebagai bahan obat. Agar tidak membingungkan karena banyaknya jenis tanaman yang dapat dijadikan obat, sebaiknya diklasifikasikan terlebih dahulu. Klasifikasi Taru Pramana yang ada di Bali dibandingkan dengan ilmu-ilmu eksakta Hindu Kuna yang ditulis oleh Prof. Dr. Tjokorda Rai Sudarta, MA, dkk memiliki kemiripan dalam klasifikasinya, antara lain;
- Wanaspati, yaitu pohon besar berbuah tanpa bunga (Pohon Beringin, Bunut, Ara, dll)

- Wriksa, yaitu pohon besar berbuah dan berbunga (Pohon Asem, Kemiri, Jeruk Bali, Cempaka, dll)

- Taru Lata, yaitu tumbuhan yang merambat (Sirih, Brotowali / Kantawali, Gadung, Tabya Bun, dll)

- Gulma, yaitu tumbuhan perdu dan semak (silaguri, awar-awar, kem, gunggum,dll)

- Trena, yaitu rumput-rumputan (alang-alang, adas, pegagagsn, kasegseg / krokot, dll)

\section{b. Sato Pramana / Bahan Obat yang Berasal dari Binatang}

Bahan obat yang berasal dari binatang, baik itu berasal dari minyaknya, kencingnya, tahinya, madunya, susunya, dll. Selain Taru Pramana sebagai sumber obat, lontar-lontar Usada menyebut seperti baem wadak / cula badak, reptil, sapi, kuda, cacing tanah, lebah, dll sebagai sumber bahan obat, yang penting bisa memilih, cara olah dan cara pakainya. (Nawa Usada Bali dan Tutur Usada)

\section{c. Toya Pramana / Bahan Obat yang Berasal dari Air}

Bahan obat yang memakai air sebagai bahan utama dan sebagai penyerta obat, yaitu air laut, air hujan, air sungai, air danau, air bendungan, air kolam, air dari buah, air perasan daun, air pancoran, embun, salju, air kencing, air cucuran atap, air susu ibu, air kumkum, dll. Toya Pramana ini terinspirasi dari lontar Usada Banyu / Usada We / Water Therapy Usada Bali.

\section{d. Bayu Pramana / Power of Mind}

Para Balian dianggap memiliki kekuatan lebih oleh masyarakat, termasuk memiliki taksu / kharisma / power of mind, sehingga balian dalam prakteknya menggunakan daya magis ini untuk kesembuhan pasiennya. Kekuatan magis ini didapatkan dari ketekunan dalam melakukan Dyana / meditasi, sembahyang, dan konsultasi dengan Balian Senior. Hal ini terinspirasi dari Usada Tiwas Punggung dan Dharma Sunia.

\section{Kepustakaan Usada}


Kepustakaan Usada Bali telah diteliti tahun 1937 oleh dokter Wolfgang Von Weck orang Jerman yang bekerja pada Pemerintahan Belanda yang berkantor di Singaraja. Kurang lebih 150 Cakep lontar sudah habis dibaca oleh timnya dan disalin dalam buku Heilkunde und Volkstum auf Bali. Kepustakaan Usada tersimpan diberbagai lembaga dan rumahrumah penduduk. Kepustakaan Usada tersebut antara lain:

- Usada Rare $\rightarrow$ Pediatric

- Usada Dalem $\rightarrow$ Internal Medicine

- Usada Edan $\rightarrow$ Psychiatry

- Usada Kacacar $\rightarrow$ Smallpox

- Usada Cukildaki $\rightarrow$ Dermatology

- Usada Kamatus $\rightarrow$ Venereology

- Usada Manak $\rightarrow$ Obstetric Genecology

- Usada Gondong $\rightarrow$ Goiter Disease

- Usada Banyu $\rightarrow$ Water Therapy

- Kuranta Bolong, Tutur Usada, Budha Kecapi / Psikologi

- Cecarcan Jadma

- Usada Taru Premana

- Usada Netra

- Usada Pengraksa Jiwa

- Tatengerin Wong Agering / Diagnosa (UPT. Lontar ; 2016, hal. 1)

\section{Tatengering Wong Agering / Diagnosa}

Dalam kepustakaan Tatengering Wong Agering disebutkan bahwa ada beberapa hal yang harus diperhatikan dengan cermat oleh para Balian sebelum menetapkan jenis penyakit yang diderita oleh pasien. Selanjutnya para Balian menentukan obatnya dan cara perawatannya.

Tatengering Wong Agering / diagnosa antara lain,

- $\quad$ Netra Pariksa $\rightarrow$ pemeriksaan pada mata pasien, seperti: warnanya, geraknya, cairan yang keluar dari matanya

- Carma Pariksa $\rightarrow$ pemeriksaan pada kulit pasien

- Nadi Pariksa $\rightarrow$ pemeriksaan pada denyut nadi pasien, keras lemahnya denyut nadi

- $\quad$ Naka Pariksa $\rightarrow$ pemeriksaan pada kuku pasien

- Jihwa Pariksa $\rightarrow$ pemeriksaan pada lidah dan mulut pasien
- $\quad$ Mutra Pariksa $\rightarrow$ pemeriksaan pada air kencing pasien, seperti volumenya, warnanya, intensitasnya, aromanya

- $\quad$ Mala Pariksa $\rightarrow$ pemeriksaan pada hasil buang air besar pasien, seperti volumenya, warnanya, bentuk dan aromanya.

\section{Pangiwa - Panengen}

Pangiwa Panengen merupakan aliran yang berkembang sehingga kadang-kadang masyarakat bertanya apakah Balian itu Panengen / Penolong atau Pengiwa / Black Magic?

Semenjak pengaruh Bhairawa mempengaruhi Bali (abad ke 13) aliran ini mulai diminati. Bhairawa jika dilihat dari tattwa nya adalah penyatuan dengan dewa Siwa yang disebut dengan Wiwaha / Sanggam. Aliran ini dibagi menjadi dua yaitu, Panengen / white magic/ Balian / pelindung / penolong. Pangiwa / black magic / perusak / penghancur / leak. Jika menjadi Balian harus berada di posisi Panengen. Hal ini banyak dimuat dalam Wraspati Tattwa, Jnana Tattwa, Ganapati Tattwa, Pangerehan, Tampur Talo (Nala, 2006, hal. 96 dan Taksu,2018, Edisi 266 Jejak Bhairawa di Bali, hal. 64)

\section{Cara Olah, Cara Pakai dan Ukuran / Takaran / Dosis dalam Usada Bali}

Terdapat beberapa cara dalam pengolahan Usada Bali, antara lain
A. Cara Olah :
1. Rebus.
2. Kukus
3. Goreng
4. Bakar
5. Remas
7. Ulek
8. Fermentasi
6. Tumbuk
dll

\section{B. Cara Pakai}

Terdapat beberapa cara dalam pemakaian / penggunaan Usada Bali, antara lain
1. Sembur / 2. Tetes / 3. Balur / Simbuh
Tutuh
Boreh
4. Minum
5. Makan
6. Hirup
7. Cocor
8. Mandi
9. Telan /
10. Tempel / Kompres
11. Oles Uluh

C. Ukuran / Takaran / Dosis

Terdapat beberapa macam ukuran / takaran / dosis dalam Usada Bali, antara lain 

1. Sehelai
2. Beberapa
Biji
3. Segenggam
7. Ukuran waktu ngunyah sirih, sehari, tiga hari
8. dll
4. Seiris
5. Sejumput
6. Sebatang

\section{Sistem Usada Bali}

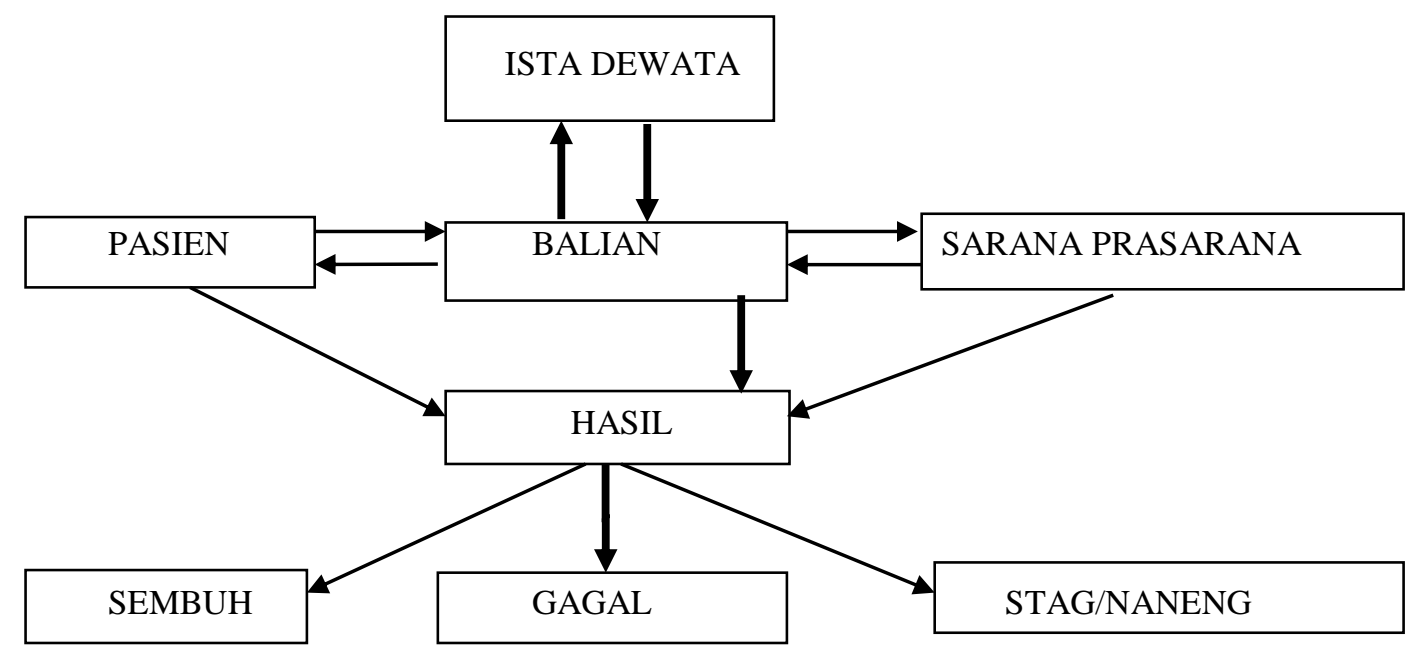

Di tengah-tengah kemapanan sistem medis modern, rupanya pengobatan Usada Bali tidak serta-merta kehilangan panggung. Masih kuatnya kepercayaan sebagian masyarakat terhadap penyebab penyakit nonmedis menjadi salah satu alasan praktik pengobatan Usada Bali masih diminati. Hal ini sejalan dengan Nala (1993:2) yang menyatakan bahwa masyarakat Hindu di Bali umumnya percaya jika penyakit dapat disebabkan oleh dua penyebab atau kausa, yakni kausa sakala dan kausa niskala. Semakna dengan pandangan Foster dan Anderson (1978:45) bahwa menurut masyarakat tradisional penyebab penyakit (etiologi) dapat dibagi menjadi dua kelompok, yakni kausa naturalistik dan kausa personalistik. Namun dalam konteks yang lain, juga kebertahanan pengobatan Usada Bali tersebut menunjukkan kemampuannya dalam beradaptasi dengan lingkungan.

\section{Regulasi Pemerintah}

Setelah lama terhegemoni oleh sistem pengobatan modern, sekarang mulai diterbitkan beberapa peraturan tentang pengobat tradisional. Dengan harapan setapak demi setapak Pengobat Tradisional Usada Bali mampu bersinergi dengan sistem pengobatan modern. Dalam Garis Besar Haluan Negara 1988 telah dicantumkan bahwa penggunaan obat dan pengobat tradisional dikembangkan terus, hal ini terkait erat dengan penggunaan biaya mahal, kita juga sebagai penerus diharapkan untuk melestarikan warisan budaya bangsa. Warisan budaya berupa pengobatan tradisional nyata-nyata telah diakui masyarakat dan nilainya perlu dikaji serta disesuaikan dengan ilmu dan teknologi yang terus berkembang.

Usada Bali sempat mengalami stagnasi yang disebabkan oleh, antara lain (1) alih fungsi lahan yang tidak terkontrol sehingga tidak tersedia lahan yang cukup untuk membudidayakan tanaman obat; (2) Taru Pramana atau tanaman obat di rumah tangga mulai digantikan dengan tanaman hias; (3) citra balian kalah dengan citra dokter; (4) kurangnya promosi; (5) sistem multilevel marketing yang mengkomersilkan obat-obatan alternatif dari luar Bali; (6) kepustakaan kesehatan tradisional terutama Ayurveda dan lontar-lontar usada berkurang peminatnya; (7) infrastruktur dan fasilitas sistem medis modern, seperti puskesmas, klinik, rumah 
sakit, alat-alat kesehatan, dan lembaga pendidikan berkembang pesat, sebaliknya infrastruktur dan fasilitas pemerintah bagi pengobatan tradisional sangat minim bahkan nihil; (8) pemberdayaan pengobatan tradisional tidak berjalan dengan baik; dan (9) masih adanya pandangan masyarakat bahwa pengobatan tradisional irasional, hanya memberikan harapan tanpa kepastian (Majalah Sarad, No. 48, Edisi April, hal. 9)

Di Bali telah pernah terbit Surat Keputusan Gubernur Kepala Daerah Tingkat I Bali Nomor 180/DIPDA/1991 tanggal 1 April 1991 , tentang pengobatan tradisional. Dengan Surat Keputusan itu Kepala Dinas Kesehatan Provinsi Bali dr. I Dewa Putu Sudana, M.Pd, membentuk tim untuk mengumpulkan tanaman-tanaman obat yang bersumber dari Usada Bali dan beberapa buku tentang tanaman obat dalam Usada Bali telah diterbitkan, belakangan terbitlah peraturanperaturan dari Kementrian Kesehatan Pusat, antara lain,

- Keputusan Menteri Kesehatan R.I. Nomor : 1076/menkes/sk/vii/2003 (tentang penyelenggaraan pengobatan tradisional)

- Peraturan Pemerintah R.I. No 103 thn 2014 (tentang pelayanan kesehatan tradisional)

- $\quad$ Peraturan Menteri Kesehatan R.I. No 9 thn 2016 (tentang upaya pengembangan kesehatan tradisional)

- $\quad$ Peraturan Menteri Kesehatan R.I. No 37 thn 2017 (tentang pelayanan kesehatan tradisional integritas)

Berdasarkan regulasi tersebut diatas terdapat pengobat tradisional / balian yang dibagi menjadi 3 kategori, yaitu (1). Pengobat Tradisional Empiris (2). Pengobat Tradisional Komplementer, dan (3). Pengobat Tradisional Terintegrasi.

\section{Usada dan Pariwisata}

Pada tahun 2001 sebanyak 30 orang wisatawan asal Swedia berkunjung ke Bali. Profesi mereka adalah sebagai pedagang bahan obat dan ramuan tradisional. Bahan obat dan ramuan yang dipakai di Swedia semuanya diimpor dari luar negeri dan tidak ada dari Indonesia / Bali, setelah di Bali mereka sangat tertarik melihat berbagai macam tanaman obat Usada Bali. Mereka juga tertarik dengan tatacara Balian terutama dalam cara urut, pijat, apun, loloh, boreh, dll
Setelah melalui perjalanan yang jauh para wisatawan dari tempat asalnya mereka akan merasa lelah setelah sampai di tujuan. Tenaga dan minat untuk segera melakukan kunjungan akan menurun, karena masih terasa lelah. Oleh sebab itu masalah ini perlu diantisipasi agar tenaganya pulih kembali. Pusat kebugaran fisik, mandi uap, minum minuman penyegar tubuh, melakukan pijat dan urut tradisional perlu diupayakan. Berbagai cendera mata dapat pula dibuat yang berkaitan dengan bagian dari tanaman usada yang dapat dipergunakan sebagai obat. Bagian dari tanaman ini dkemas sedemikian rupa sehingga menarik dan tahan lama. Mandi di pancuran kolam atau mandi spa misalnya yang memanfaatkan berbagai bunga serta ramuan usada sebagai tambahannnya. Industri pariwisata dapat mengemas hal-hal tersebut sedemikian rupa dengan cara dimodifikasi dari bahan alami, sehingga layak dijual untuk kepentingan wisatawan. (Nala, makalah Usada Bali dan Pariwisata)

\section{Kesimpulan dan Saran}

\section{a. Kesimpulan}

Berdasarkan uraian dan penjelasan diatas maka dapat ditarik beberapa kesimpulan, yaitu

1. Usada sebagai warisan budaya di bidang pengobatan tradisional Bali, perlu dikembangkan sesuai dengan kemajuan ilmu pengetahuan dan teknologi.

2. Usada merupakan bagian sistem pengobatan holistik dalam multikulturalisme yang bercirikan kebutuhan akan pengakuan dan legitimasi keragaman budaya pengobatan.

3. Bali sebagai daerah tujuan pariwisata dunia berpeluang mengangkat Usada atau pengobatan tradisional sebagai salah satu penunjang pariwisata di Bali

\section{b. Saran}

Untuk kemajuan Usada Bali hendaknya para cendikiawan di bidang kesehatan melakukan penelitian lebih intensif. Regulasi perlu disikapi secara positif agar Usada Bali selangkah demi selangkah semakin maju. Pelaku pariwisata hendaknya memperhatikan Usada Bali sebagai aset budaya yang telah mengakar di masyarakat etnis Bali, layak diperkenalkan dan ditawarkan sebagai salah satu penunjang kepariwisataan di Bali. 


\section{DAFTAR PUSTAKA}

Dinas Kesehatan Propinsi Daerah Tingkat I Bali. 1991/1992. Tanaman Obat Dalam Lontar Usada Vol. VIII. Denpasar

Dinas Kesehatan Propinsi Daerah Tingkat I Bali. 1992/1993. Tanaman Obat Dalam Lontar Usada Vol. IX. Denpasar

Foster and Anderson. 1978. Antropologi Kesehatan. UI Press. Jakarta

Kantor Dokumentasi Kebudayaan Bali. 1996. Bhuwana Mahbah. Denpasar

Mbete, Aron Meko. 1988. Proses dan Protes Budaya. BP. Press. Denpasar

Nala, N. 1993. Usada Bali. PT. Upada Sastra. Denpasar

2006. Usada Bali dan Pariwisata. Universitas Hindu Indonesia. Denpasar

Prastika, I Nyoman. 2017. Yoga Sastra Laku Mistik Balian Usada Bali (Disertasi). Universitas Hindu Indonesia. Denpasar
Pulasari, Jro Mangku. 2009. Nawa Usada Bali, Paramita Surabaya

Sudira, I Made. 1997. Tutur Usada. Paramita Surabaya

Sudharta, Tjok Rai. 2001. Ilmu-ilmu Pengetahuan Eksakta Hindu Kuno. Paramita Surabaya

Triguna, IBG Yudha. 2008. Kebudayaan dan Modal Budaya Bali Dalam Teropong Lokal, Nasional, Global. Widya Dharma Denpasar

Weck, Wolfgang von. 1937. Heilkunde und Volkstum auf Bali. Niederlandisch

Majalah

Majalah Usadha, Edisi I. 2007

Majalah Suara Balian, Volume I. 2008

Majalah Taksu, Edisi 266. 2018

Majalah Sarad, Edisi April no. 48. 2004

Koran

Jawa Pos, Radar Bali. 11 November 2018 